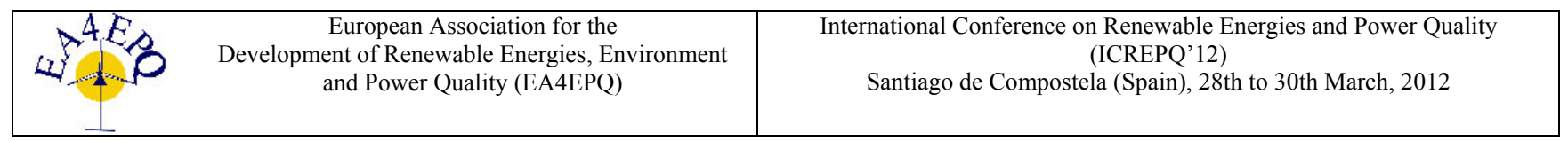

\title{
Research on Control Strategies of a Stand-alone Photovoltaic System
}

\author{
Qiu Bin and Ma Yundong \\ Jiangsu Key Laboratory of New Energy Generation and Power Conversion \\ , Nanjing University of Aeronautics and Astronautics \\ \#29 Yudao Street, Baixia District, Nanjing, Jiangsu Province, China \\ Phone number: +86 13914491319, e-mail: nuaaqb@yahoo.cn, kyleo@nuaa.edu.cn
}

\begin{abstract}
In order to assure that the system can run stably under different modes, energy storage equipment-Lead-Acid battery is added to the conventional two-stage PV system. PV panels and batteries are parallel connected to the DC-bus through a unidirectional Boost converter and a bidirectional Buck/Boost converter respectively. A full bridge inverter is linked to the DCbus as the second stage of the system which is in charge of DC$\mathrm{AC}$ power transforming for the AC loads. Control methods and power management strategies of a two-stage stand-alone photovoltaic system are proposed in this paper. A $500 \mathrm{~W}$ experiment prototype is constructed to verify the theoretical analysis of the control methods and power management strategies.
\end{abstract}

\section{Key words}

AC PV system, MPPT(Maximum Power Point Tracking), Stand-alone mode, Power management.

\section{Introduction}

Considered as one of the most luxuriant renewable energy, solar energy has its own unique superiority and tremendous potential in development and utilization. According to the various energy conversion ways, solar energy is mainly applied in the following three fields: solar-heat conversion domain (Solar water heaters, solar heat power generation etc.), solar-electricity conversion domain (Photovoltaic power generation etc.) and solarbiology conversion domain (Photo-biological hydrogen production etc.).Among them, PV power generation is the prime style of solar utilization.

A PV system which is not connected to the grid is called a stand-alone PV system, which can be classified into the DC stand-alone PV system and the AC standalone PV system in terms of the different output voltage forms. AC PV system is concentrated in this paper. As solar energy is the solitary energy source in the standalone PV system, an energy storage element should be attached to serve as an energy regulator of the system, so a manageable stand-alone PV system is composed, which has following merits:
A. Besides supplying power to local loads and grid, the system can act as a backup UPS (Uninterrupted Power Supply) when PV panels are short of power.

B. Large-scale grid-connected manageable PV systems can regulate the peak power of the grid under permitted condition.

C. The storage element can protect the steady DCbus voltage from the output voltage interference of PV panels owing to the dynamic climate.

Control methods and power management strategies of a stand-alone PV system are primarily discussed in this paper. System structure and working modes are analyzed in detail firstly, then control methods of the converters in the system and power management tactics are made, at last, simulation based on Matlab/Simulink and experiment of the prototype are executed to verify the theoretical analysis.

\section{System structure and operational modes}

The topologic structure of the management standalone PV system is shown in Fig.1, which consists of PV panels, batteries, load, and the converters which connects the terminals. PV panels and battery can co-ordinate to supply power to the load through controlling the unidirectional Boost converter and the bidirectional converter in the system. There are four operational modes in the system according to the different working statuses of PV panels and battery, whose power flow diagrams are presented in Fig. 2:

\section{A. $\quad$ Mode 1:}

As is shown in Fig. 2a, unidirectional Boost converter shuts down in case that solar illumination is too weak to motivate PV panels transfer power. If battery is over-discharged simultaneously, in order to protect it, the bidirectional Buck/Boost converter must stop working, as a result, the system is in a shutdown state in this mode. 


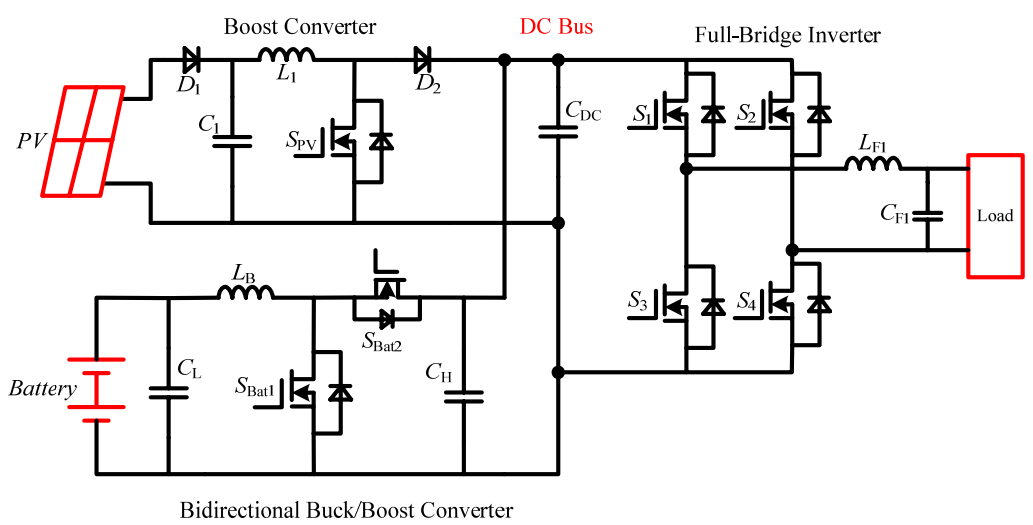

Fig.1. Topologic structure of the stand-alone PV system.

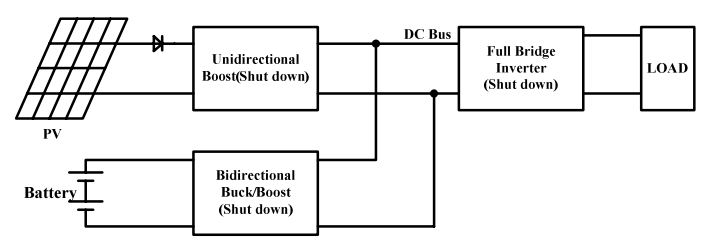

Fig. 2a Mode 1.

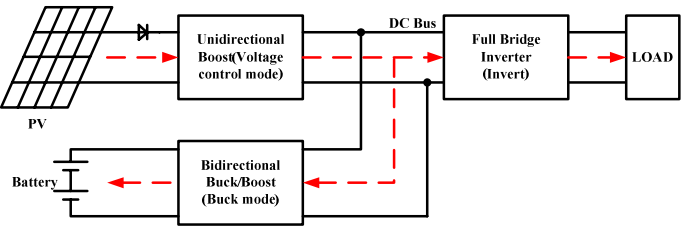

Fig. 2c Mode 3.

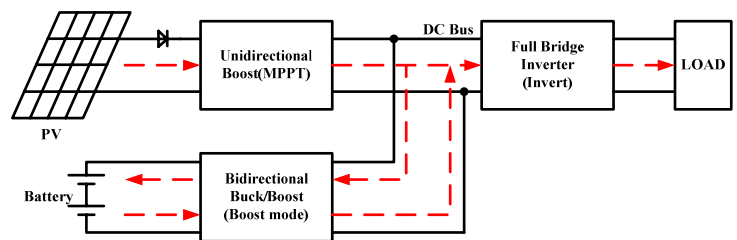

Fig. 2b Mode 2.

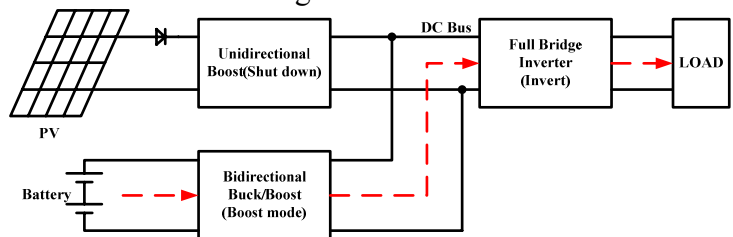

Fig. 2d Mode 4.

Fig.2 Power flow diagram of each mode.

\section{B. Mode 2:}

The power flow diagram of mode 2 is shown in Fig. $2 \mathrm{~b}$. The unidirectional Boost converter works in the MPPT mode to realize PV panels' MPPT as the system runs normally; the bidirectional Buck/Boost converter works in the Boost mode simultaneously while DC-bus voltage is maintained stable through controlling high-side voltage and discharging current of the battery. The battery supplies the lacking power to the load via bidirectional converter when output power of PV panels can't meet load demand, battery is in the discharge state in this case; On the contrary, if PV panels' output power exceeds load's required power, the rest power is used to charge the battery, which is in a status of charging.

\section{Mode 3:}

In mode 2 , once the battery voltage reaches overcharge voltage or the charge current of the battery exceeds maximum charge current, the two quantities(low-side voltage of the bidirectional converter and charge current of the battery) need to be limited to protect the battery, based on which, the bidirectional converter must transfer from Boost mode to Buck mode. The unidirectional Boost converter should also turns from MPPT mode to voltagecontrol mode to maintain the DC-bus voltage correspondingly. The process diagram of mode 3 is exhibited in Fig. 2c.

\section{Mode 4:}

As Fig. 2d displays, PV panels have no ability to output power in a very weak illumination condition, the battery acts as the sole energy source to provide power to the load if enough power remains in the battery at that time. As a result, the unidirectional Boost converter shuts down as the bidirectional Buck/Boost converter is in the Boost mode through controlling the high-side voltage and the discharge current of the battery.

Through measuring PV panels' output voltage, battery's terminal voltage and the charge/discharge current of the battery, the operational mode of the system can be determined by the energy management circuit, so corresponding control strategies can be applied to the system.

\section{Overall control strategies}

The two DC/DC converters in the system need to coordinate to work. The blocks diagram of the overall control strategies of the system is shown in Fig. 3. As is shown in the figure, PV panels' voltage, the terminal voltage and charge current of the battery are sampled to the energy management circuit which outputs the following signals: the shutdown signal of the unidirectional Boost converter ( $\left.V_{\text {Boost_SD }}\right)$, the shutdown signal of the bidirectional Buck/Boost converter $\left(V_{\mathrm{Bi}} \mathrm{SD}\right)$, the shutdown signal of the full bridge inverter and the 
mode select signal of the system $\left(\mathrm{V}_{\text {mode_select }}\right)$. When the system works in mode 2 or in mode 3 mentioned above, all three converters in the system work regularly and the respective shutdown signal is in the low level; When it's in mode 4, the unidirectional Boost is shutdown, so the corresponding shutdown signal $V_{\text {Boost_SD }}$ is in the high level; Then if it's in mode 1, all three converters stop working, which causes all three shutdown signals in high level.

As the system runs in mode 2 or mode 3 , the specific working statuses of the unidirectional Boost converter and the bidirectional Buck/Boost converter are determined by the mode select signal ( $\left.V_{\text {mode_select }}\right)$. In case that it's in low level, the unidirectional converter is in the voltage-control mode to sustain the DC-bus voltage, correspondingly, to avoid battery's over-charge, the bidirectional converter works in the Buck mode to limit the terminal voltage and charge current of the battery. On the contrary, when $V_{\text {mode_select }}$ is in high level, the unidirectional converter works in MPPT mode to realize MPPT of PV cells, the bidirectional converter transfers to Boost mode to maintain the DC-bus voltage simultaneously.

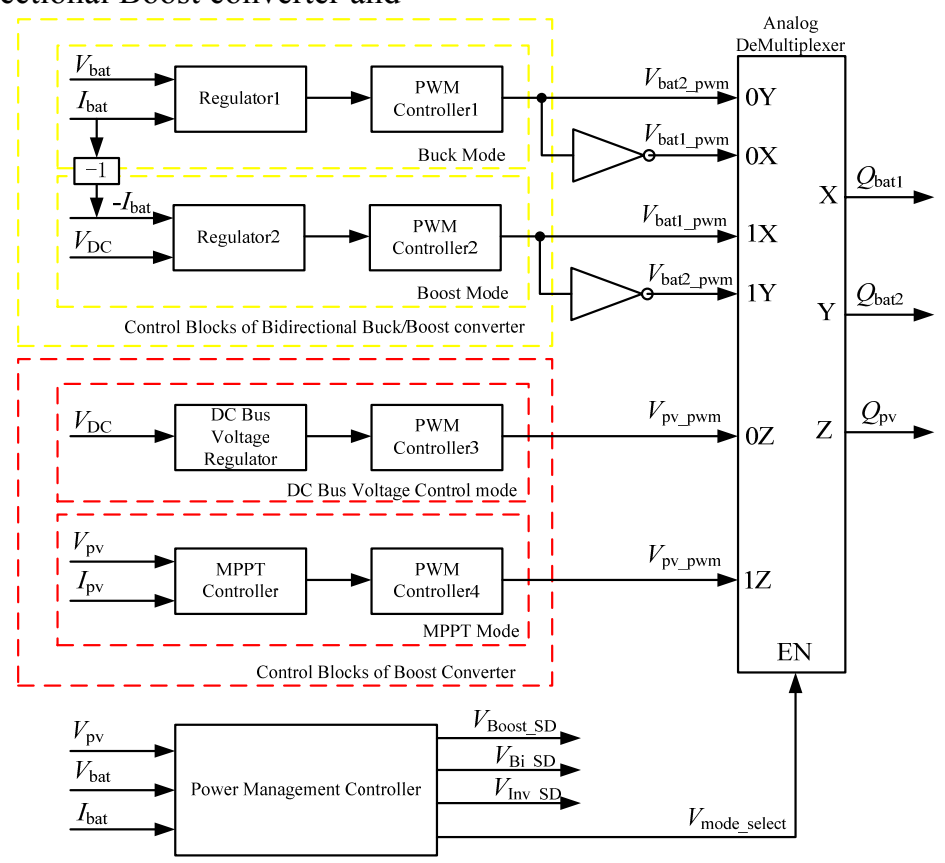

Fig. 3. Overall control strategies of the stand-alone PV system.

As Fig. 3 shows, when $V_{\text {mode_select }}$ is in low level, the three output signals of the analog demultiplexer chip are corresponding to the drive signals which are input to the ports $0 \mathrm{X}, 0 \mathrm{Y}$ and $0 \mathrm{Z}$, which are used to be the drive signals of switching transistors $S_{\text {bat1 }} 、 S_{\text {bat2 }}$ and $S_{\mathrm{pv}}$ respectively. Also, when $V_{\text {mode_select }}$ is in high level, the drive signals of the three switching transistors $S_{\text {bat1 }} 、 S_{\text {bat2 }}$ and $S_{\mathrm{pv}}$ are respectively three signals which are input to the three input ports $1 \mathrm{X}, 1 \mathrm{Y}$ and $1 \mathrm{Z}$ of the demultiplexer chip.

\section{Specific control strategy of the inverter}

The inverter should output a stable sinusoidal voltage for the load as it runs independently. The two loops (inner inductor current loop and outer output voltage loop) control strategy is adopted in this inverter. The blocks diagram of the control system is shown in Fig. 4, where $L_{\mathrm{F} 1}$ and $C_{\mathrm{F} 1}$ are respectively values of the output filter inductor and capacitor, $R_{\mathrm{L}}$ is the value of load resistor, $k_{\mathrm{v}}$ and $k_{\mathrm{i}}$ are feedback coefficients of output voltage and inductor current, while $G_{\mathrm{cv}}(\mathrm{s})$ and $G_{\mathrm{ci}}(\mathrm{s})$ represent the open loop transfer functions of the voltage loop and current loop separately.
The open loop transfer function of the inner inductor current loop is:

$$
G_{\mathrm{i} 2}(s)=\frac{k_{\mathrm{PWM}} \cdot k_{i}}{L_{\mathrm{F} 1} s\left(T_{\mathrm{d}} s+1\right)} \cdot G_{\mathrm{Ci}}(s)
$$

Setting regulator of inner inductor current loop as a proportional one, so the open loop transfer function of the current loop is:

$$
G_{\mathrm{Ci}}(s)=k_{\mathrm{pi}}
$$

So it can be concluded from formula (1) and (2) that the transfer function of inner current loop is type I, which can be described as formula (3):

$$
G_{\mathrm{i} 2}(s)=\frac{k_{\mathrm{pi}} \cdot k_{\mathrm{PWM}} \cdot k_{i}}{L_{\mathrm{F} 1} s\left(T_{\mathrm{d}} s+1\right)}=\frac{k_{\mathrm{i} 2}}{s\left(T_{\mathrm{i} 2} s+1\right)}
$$

In formula (3), $k_{\mathrm{i} 2}=\frac{k_{\mathrm{pi}} \cdot k_{\mathrm{PWM}} \cdot k_{\mathrm{i}}}{L_{\mathrm{F} 1}}, T_{\mathrm{i} 2}=T_{\mathrm{d}}=\frac{T_{\mathrm{s}}}{2} \cdot T_{\mathrm{s}}$ is the cycle time of the carrier wave. Assuming that $k_{\mathrm{i} 2} T_{\mathrm{i} 2}=0.5$, the proportional coefficient of inner current loop can be derived as formula (4) :

$$
k_{\mathrm{pi}}=\frac{L_{\mathrm{F} 1}}{k_{\mathrm{PWM}} k_{\mathrm{i}} T_{\mathrm{s}}}
$$


Through synthesizing all the formulas above, the closed loop transfer function of the inner current loop is concluded as formula (5) :

$$
\Phi_{\mathrm{i} 2}(s)=\frac{1 / k_{\mathrm{i}}}{\frac{T_{\mathrm{i} 2}}{k_{\mathrm{i} 2}} s^{2}+\frac{1}{k_{\mathrm{i} 2}} s+1} \approx \frac{1 / k_{i}}{\frac{1}{k_{\mathrm{i} 2}} s+1}=\frac{1 / k_{i}}{T_{\mathrm{s}} s+1}
$$

Based on formula (5), the open loop transfer function of the outer voltage loop can be deduced as formula (6) under empty load condition:

$$
G_{\mathrm{v}}(s)=\frac{k_{\mathrm{v}} / k_{\mathrm{i}}}{C_{\mathrm{F} 1} s\left(T_{\mathrm{s}} s+1\right)} \cdot G_{\mathrm{cv}}(s)
$$

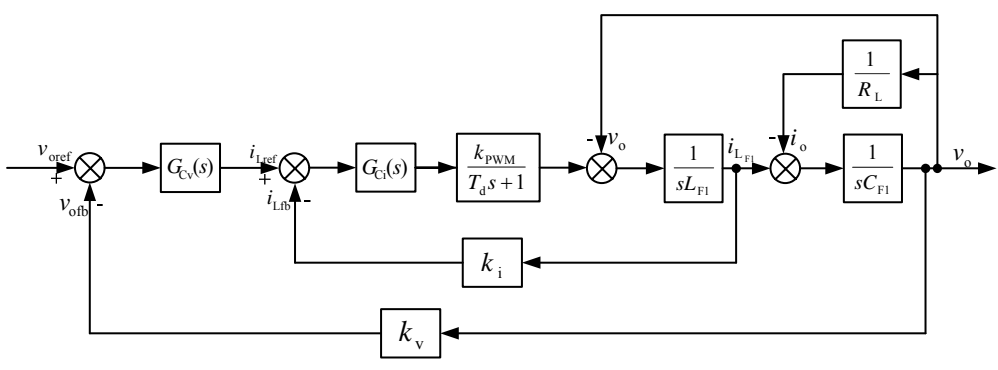

Fig. 4. Blocks diagram of inverter control strategy

In order to set the transfer function as type II, the regulator of the voltage loop needs to be designed as a PI regulator, whose transfer function is shown below:

$$
\mathrm{G}_{\mathrm{cv}}=\frac{\tau_{2} s+1}{\tau_{1} s}
$$

So the open loop transfer function of the outer voltage loop can be derived as formula (8) shows:

$$
G_{\mathrm{v}}(s)=\frac{k_{\mathrm{v}}\left(\tau_{2} s+1\right)}{k_{\mathrm{i}} C_{\mathrm{F} 1} \tau_{1} s^{2}\left(T_{\mathrm{s}} s+1\right)}=\frac{k_{\mathrm{v} 1}\left(\tau_{2} s+1\right)}{s^{2}\left(T_{\mathrm{s}} s+1\right)}
$$

The parameters of the PI regulator are adjusted referring to the typical type II system, the width of medium frequency region is set as $h=5$, so formula (9) is deduced:

$\tau_{2}=h T_{\mathrm{s}}=5 T_{\mathrm{s}}$
While $k_{v 1}=\frac{h+1}{2 h^{2} T_{s}^{2}}=\frac{3}{25 T_{s}^{2}}$, parameter $\tau_{1}$ is calculated as:

$$
\tau_{1}=\frac{k_{\mathrm{v}}}{k_{\mathrm{v} 1} k_{\mathrm{i}} C_{\mathrm{F} 1}}=\frac{25 k_{\mathrm{v}} T_{\mathrm{s}}^{2}}{3 k_{\mathrm{i}} C_{\mathrm{F} 1}}
$$

The specific parameters of the outer voltage loop's PI regulator are determined by formula (9) and (10).

\section{System simulation}

The simulation model of the system is built in Matlab to prove the effectiveness of the control strategies. The maximum power point voltage of the model is $V_{\mathrm{m}}=138 \mathrm{~V}$, while the maximum power value is $P_{\mathrm{m}}=620 \mathrm{~W}$, and the rated power of the load in the model is $P_{\mathrm{L}}=500 \mathrm{~W}$. Some other simulation parameters of the model are listed below: the DC-bus voltage reference $U_{\mathrm{dcref}}=400 \mathrm{~V}$; the input filter capacitor of the unidirectional Boost converter $C_{\mathrm{pv}}=220 \mu \mathrm{F}$, the inductor of the unidirectional converter $L_{1}=700 \mu \mathrm{H}$, the DC-bus filter capacitor $C_{\mathrm{dc}}=1000 \mu \mathrm{F}$, output filter inductor and capacitor values of the inverter are $L_{\mathrm{F} 1}=950 \mu \mathrm{H}$, $C_{\mathrm{F} 1}=5 \mu \mathrm{F}$, Switching frequency of the two DC-DC converters is $100 \mathrm{kHz}$, Switching frequency of the inverter is $f_{\mathrm{s}}=25 \mathrm{kHz}$. The rated load voltage is $220 \mathrm{~V} / 50 \mathrm{~Hz}$.
Parameters of the inverter regulator: The proportional coefficient of the inner current loop regulator $k_{\mathrm{p} 2}=1$, proportional coefficient of the outer voltage loop regulator $k_{\mathrm{pv}}=1$, integral coefficient of the outer voltage loop regulator $k_{\mathrm{iv}}=600$.

\section{A. $\quad$ Case 1 (rated load condition)}

The simulation waveforms under rated load condition are shown in Fig. 5.

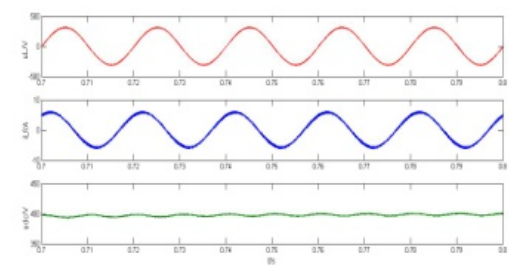

Fig. 5a. Load voltage, inductor current and DC-bus voltage waveforms.

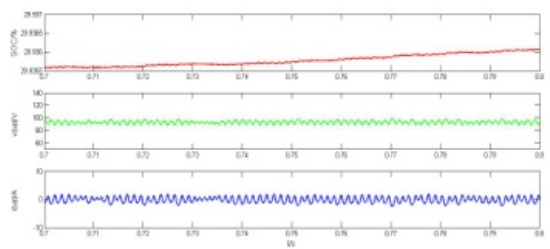

Fig. 5b. Parameters of the battery.

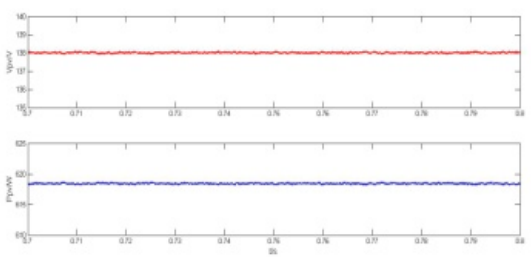

Fig. 5c. PV panels voltage and output power waveforms.

Fig. 5. Simulation waveforms under rated load condition.

The three waveforms in Fig. 5a are respectively load voltage, inductor current and DC-bus voltage from top to bottom. As is shown in Fig. 5a, the load voltage is 
maintained at $220 \mathrm{~V} / 50 \mathrm{~Hz}$ while DC-bus voltage is stable at $400 \mathrm{~V}$ with a little voltage ripple.

Waveforms of state of charge (SOC), terminal voltage and discharge current of the battery are shown in Fig. $5 \mathrm{~b}$ from top to bottom. When the system runs in steady state, battery is in charge as PV panels' output power exceeds load's need, which results in SOC of the battery increment.

The waveforms displayed in Fig. 5c are separately the voltage and output power of PV cells, which works steadily at $138 \mathrm{~V}$ and $620 \mathrm{~W}$, so it can be concluded that PV cells are working at the maximum power point.

\section{B. Case 2 (twice load condition)}

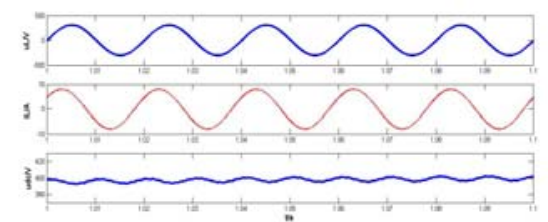

Fig. 6a. Load voltage, inductor current and DC-bus voltage waveforms.

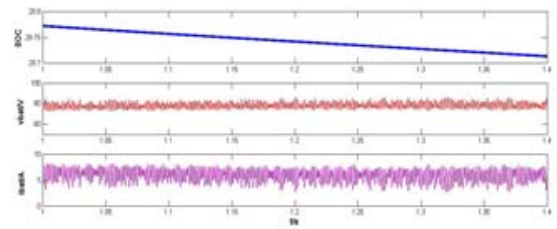

Fig. 6b. Parameters of the battery.

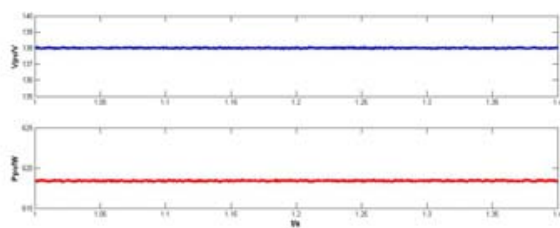

Fig. 6c. PV panels voltage and output power waveforms.

Fig. 6. Simulation waveforms under heavy load (twice load) condition.

Simulation waveforms under heavy load (twice load) condition are shown in Fig. 6.

The waveforms proposed in Fig. 6 are in the same sequence as in Fig. 5. The power output by PV panels can't satisfy load's requirement under twice load condition. So the battery is in discharge state to sustain the load power, which results in the reduction of SOC (state of charge) of the battery.

Simulation results prove the effectiveness of the control strategies proposed above.

\section{Experiment results}

A $500 \mathrm{~W}$ experiment prototype is built to test how the control strategies work. Detailed parameters are listed below:

Switching frequency of unidirectional converter and bidirectional converter: $100 \mathrm{kHz}$.

Rated load power: 500W.
Switching frequency of inverter: $25 \mathrm{kHz}$.

Rated DC-bus voltage: $350 \mathrm{~V}$.

Parameters of PV cells: Rated temperature: $25^{\circ} \mathrm{C}$, Open circuit voltage: $V_{\mathrm{OC}}=175 \mathrm{~V}$, Short circuit current: $I_{\mathrm{SC}}=5.7 \mathrm{~A}$, Maximum power point voltage: $V_{\mathrm{m}}=138 \mathrm{~V}$, Maximum power point current: $I_{\mathrm{m}}=4.5 \mathrm{~A}$.

Parameters of the battery: Rated capacity: 20Ah; Rated voltage: $96 \mathrm{~V}$.

The rest parameters of the prototype are the same as that shown in simulation models in last section.
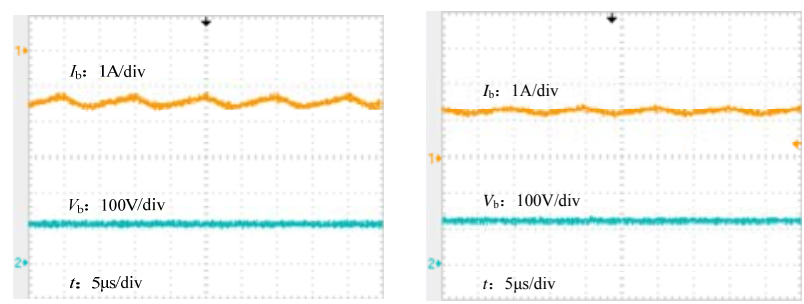

Fig. 7. Terminal voltage of the battery and inductor current waveforms of bidirectional converter in different states.

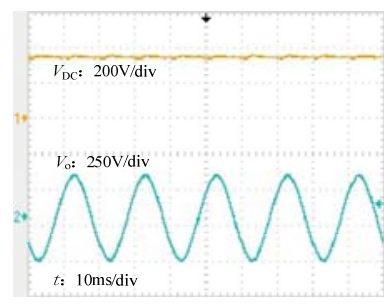
voltage and drive voltage waveforms.
Fig.8. DC-bus voltage, load

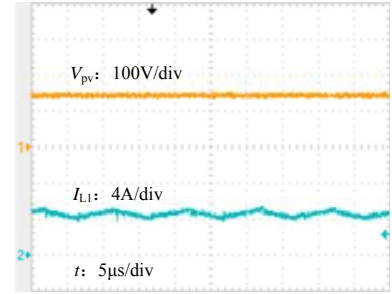

Fig.9.Output voltage and current waveforms of PV panels.
As is shown in Fig. 7, the left figure are waveforms of inductor current $\left(I_{\mathrm{b}}\right)$ of bidirectional converter and terminal voltage $\left(V_{\mathrm{b}}\right)$ of the battery as the battery is in charge state. The waveforms photo was taken under rated load condition $(500 \mathrm{~W})$. In this condition, the PV cells output power is more than load's need, so the battery are in charge state. As indicated in the figure the inductor current is a negative value.

The waveforms shown in the right part of Fig. 7 are in the same sequence as that shown in the left part, which were taken under heavy load condition $(800 \mathrm{~W})$. The battery is in discharge status to support the load's requirement.

Waveforms shown in Fig. 8 are separately DC-bus voltage $\left(V_{\mathrm{DC}}\right)$ and load voltage $\left(V_{\mathrm{o}}\right)$ from top to bottom. The DC-bus voltage is sustained at $350 \mathrm{~V}$ with a little ripple while the load voltage is uniform sinusoidal wave at $220 \mathrm{~V} / 50 \mathrm{~Hz}$.

The top waveform in Fig. 9 is the output voltage $\left(V_{\mathrm{pv}}\right)$ waveform of the PV cells and the corresponding inductor current $\left(I_{\mathrm{L} 1}\right)$ waveform of the unidirectional Boost 
converter is displayed in the bottom of Fig. 9. The value of $V_{\mathrm{pv}}$ is maintained about $138 \mathrm{~V}$ and the average value of $I_{\mathrm{L} 1}$ is nearly 4.5A. So PV panels's MPPT is realized and the unidirectional Boost coverter works in MPPT mode simultaneously.

It can be summarized from the prototype waveforms that the stand-alone PV system can run smoothly under different load conditions to provide the power required by the load.

\section{Conclusion}

The storage element - lead acid battery is added to the conventional two-stage stand-alone PV system to increase the flexibility and stability of the system. Also, system structure, operational modes and control strategies are proposed in this paper, among which detailed control parameters calculation of the inverter is discussed. At last, simulation and prototype waveforms prove that the stand-alone PV system is feasible and the control strategies are effective.

\section{References}

[1]. Park J H, Ahn J Y, Cho B H and Yu G J. "Dual-ModuleBased Maximum Power Point Tracking Control of Photovoltaic Systems," IEEE Trans. Ind. Electron., Vol 53, No.4, 2006, pp.1036-1047.

[2]. Koizumi H and Kurokawa K. "A Novel Maximum Power Point Tracking Method for PV Module Integrated Converter,” In Proc.IEEE PESC, 2005, pp.2081-2086.

[3]. Duryea S, Islam S and Lawrance W. "A Battery Management System for Stand-alone Photovoltaic Energy Systems," IEEE Industry Applications Magazine, Vol 7, No.3, pp.67-72.

[4]. Park Sung-Yeul,Lai Jih-Sheng,Chen Chien-Liang. Current loop control with admittance compensation for a singlephase grid-tie fuel cell power conditioning system[C].IEEE $22^{\text {nd }}$ Annual Conference on Applied Power Electronics, 25, Feb, 2007: 645-660.

[5]. Pacheco V M, Freitas L C, Vieira J B, Coelho E A A and Farias V J. "Stand-alone Photovoltaic Energy Storage System with Maximum Power Point Tracking," In Proc. IEEE APEC, 2003, pp.97-102. 